\title{
Editorial:
}

\section{Coevolución entre revoluciones industriales y ciencias económicas y administrativas}

\author{
Coevolution of Industrial Revolutions and Economic and Management Sciences
}

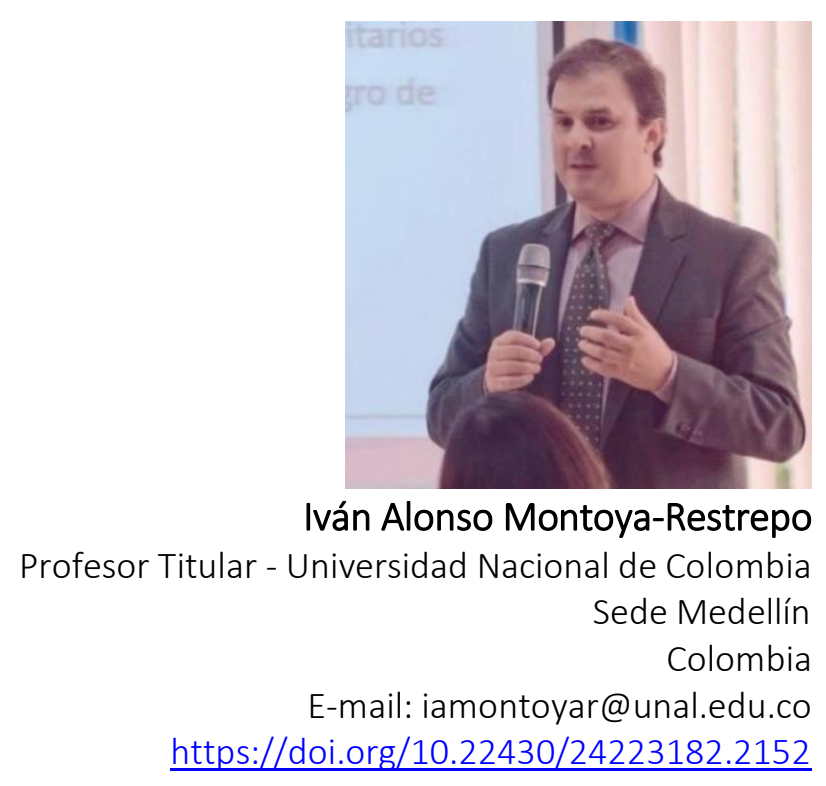

La naciente cuarta revolución industrial, quizás propulsada por las consecuencias de la enfermedad COVID-19, se nos aparece hoy en día como un gran salto en el cual convergen desarrollos tecnológicos de las aplicaciones en información y comunicaciones (Rozo- García, 2020), pero también nuevas complejidades en la combinación del uso de los recursos, para generar procesos colaborativos orientados hacia la generación de capacidades, aprendizajes y adaptabilidades de las organizaciones hacia las volatilidades del entorno y los mercados. Convergencias asistidas por inteligencia artificial de dominios físicos, biológicos y digitales, relacionados digitalmente por formas de interacción nuevas y más económicas (Rozo- García, 2020), nos llevan a pensar en el presente de los mercados del dato y de las redes inteligentes, así como en las transformaciones en la producción, el empleo, la distribución de la riqueza sobre la base de posibles monopolios y la emergencia de nuevas condiciones para el acceso a los mercados a través de eventuales barreras a la entrada. 
Estos avances y retos son también, en cierta forma, la consecuencia de una trayectoria de procesos evolutivos, prósperos y regresivos, en los cuales se ha consolidado el modo contemporáneo de capitalismo liberal, que involucra una mayor profundidad en los procesos de división funcional del trabajo en la práctica, pero también novedades en las visiones de mundo, en las explicaciones teóricas y en los métodos de trabajo y pensamiento, sobre el papel de mercados, organizaciones e instituciones en las rutas del «desarrollo» civilizatorio de la producción, la distribución y el consumo de bienes, con los retos de una población creciente.

El avance de las ciencias económicas y administrativas ha venido desplegándose a la par con una mayor profundidad en la aplicación de la división del trabajo y en el desarrollo de las fuerzas productivas que se derivan estas. Los orígenes del pensamiento económico se pueden ubicar junto al surgimiento del liberalismo como doctrina filosófica, con la expansión del comercio internacional, la revolución agrícola, el nuevo papel del mercado como mecanismo de asignación de la justicia social, pero especialmente, como parte de los cambios productivos que propiciaron la emergencia de la primera revolución industrial impulsada por la aplicación de esta poderosa idea de la división del trabajo.

Las implicaciones no solamente se contaron alrededor de una revolución moral intensa hacia el ánimo de lucro y el papel de los mercados, sino también hacia la búsqueda de mayor productividad y sus repercusiones en cambios institucionales y sociales, los cuales también llevaron a una mayor diferenciación entre las ciudades y los entornos rurales, a la especialización de las naciones por actividades productivas a través de las ventajas comparativas y a la búsqueda de una mayor eficiencia en la transición de actividades artesanales para empezar a desarrollarse procesos de manera fabril. La división del trabajo, como motor de la conversión industrial, se convirtió en explicación clave sobre el origen de la prosperidad de las naciones, como diría Adam Smith, mientras que los mecanismos de asignación a través de los mercados pusieron en marcha los ideales del liberalismo y el individualismo en las elecciones, los cuales condujeron a asentar las bases de la industrialización capitalista, derivando esta, a la postre, en la cultura comercial contemporánea, en el actual funcionamiento de las ciudades como centros densa y crecientemente poblados, en una mayor acumulación de capital y una mayor eficiencia productiva, como sugiere (Hartwell, 1971), y además, en la transformación hacia nuevos hábitos y estilos de vida que implicaron conseguir, a su vez, nuevas formas de dinamismo para incrementar la demanda de los recientes productos fabricados.

Para finales del siglo XIX y comienzos del siglo XX, la consolidación de los avances científicos y tecnológicos, entre ellos las invenciones en cuanto al empleo de electricidad, el acero, la industria química, los motores de combustión y los transportes, aunado todo esto a la expansión de las nuevas naciones y al surgimiento del capital financiero (como la combinación de los capitales industriales y bancarios), gestó una profundización en los usos de la división del trabajo y disparó la segunda revolución industrial, caracterizada por una mayor especialización funcional (Ramón- Muñoz, 2012) y a la descomposición de las actividades en tiempos y movimientos con miras a la búsqueda de una mayor productividad por vías de la repetición de tareas. Allí se encuentran también los orígenes de las ciencias administrativas, profundamente vinculadas desde sus comienzos con encontrar explicaciones sobre cómo establecer mecanismos coordinadores y división del trabajo entre empleados y empleadores en las organizaciones, para el logro de mayores niveles de productividad y eficiencia (Taylor, 1969). 
El crecimiento de la productividad logrado por la segunda revolución industrial, la expansión de la oferta, y luego la contracción del consumo con la gran depresión, las consecuentes políticas para conjurar la crisis mediante la expansión estimulada de la demanda en un periodo de intensa agitación por cuenta de una dramática transición de poderes políticos y económicos en las guerras mundiales, condujo al desarrollo y la incorporación de progresos científicos que prorrumpieron en la tercera revolución industrial, usualmente enmarcada desde la segunda guerra mundial y hasta la crisis del petróleo (Roel Pineda, 1998) y, para otros, hasta el surgimiento de la economía neoliberal. La tercera revolución se desató alrededor de los sistemas, la cibernética, la innovación y los progresos de la ciencia basados en el desarrollo experimental; asimismo, esta transformación preparó el camino para un mercado de productos e inversiones realmente globalizado, hipercompetitivo, con nuevas barreras a la entrada fundadas en la gestión de los costos y la diferenciación, y posibilitó la disponibilidad de nuevas escalas productivas y medios de comunicación y transporte que viabilizaron la emergencia de corporaciones globales.

La desregulación surgida desde la crisis del petróleo, el petrodólar y la política de estímulos a la oferta de la revolución conservadora en la década de los ochenta, entre otros ha empujado, a partir de la década de los noventa, los últimos 30 años de economía neoliberal, en la cual la lógica de los mercados se ha vuelto el discurso predominante con intensas implicaciones en dimensiones como salud, educación, contaminación, hambre y desnutrición, empleo e inclusión, por mencionar solamente algunas. La evolución hacia la industria 4.0 es en buena parte el fruto de los procesos emergentes en automatización, telecomunicaciones, electrónica y bioingeniería que surgieron en la tercera revolución, y que con los avances en computación, digitalización, robótica y nuevos materiales (Schwab, 2016), auguran una mayor integración digital de procesos recursivos en la producción industrial. Economías circulares, nuevas formas de combinación compleja de recursos y procesos para darle versatilidad a la innovación, ciclos productivos de altísimo aprovechamiento de los recursos y su gestión en tiempo real, parecen ser los nuevos estándares del diseño de procesos.

Las repercusiones pueden resultar aun difíciles de anticipar, pero quizás la cuarta revolución traerá nuevos modelos de negocios basados en la generación, uso y apropiación de información modelada para toma de decisiones online en el marco de la redefinición de las lógicas urbano-rurales que impliquen nuevas configuraciones de sistemas agroalimentarios y logísticos o nuevas estructuras de gobernanza en localidades y territorios en medio de emergentes formas de generación de riqueza protegidas por barreras centradas en la gestión del conocimiento experto, cualificado y en tiempo real, y en los montos de las inversiones para acceder a la producción y al mercado en industrias especializadas. Quizás muchos de los retos tengan también que ver con la posibilidad de mayores desigualdades interregionales, repentinas formas de desempleo y mayores dependencias tecnológicas. El reto central parece ser el de fomentar el buen vivir, sin que las transformaciones emergentes generen límites a la libertad del espíritu del ser humano. 
Editorial

\section{REFERENCIAS}

Hartwell, R. M. (1971). La Revolución Industrial en Inglaterra y sus consecuencias para los pobres. URL

Ramon-Muñoz, R. (2012). Guerras, crisis y derrumbamiento de la primera globalización (1914-1950). Universitat Oberta de Catalunya (OUC).

Roel Pineda, V. (1998). La tercera revolución industrial y la era del conocimiento. (3ra ed.). Fondo Editorial UNMSM.

Rozo-García, F. (2020). Revisión de las tecnologías presentes en la industria 4.0. Revista UIS Ingenierías, v. 19, n. 2, 177-192. https://doi.org/10.18273/revuin.v19n2-2020019

Schwab, K. (2016). La cuarta revolución industrial. Foro Económico Mundial (Debate). Casa Editorial El Tiempo, S.A. URL

Taylor, F. W. (1969). Principios de la Administración científica. (11ma.). Herrero Hnos. S. A. 